\title{
A arte do remix: uma anarqueologia dos processos de criação em mídias digitais ${ }^{1}$
}

\section{The art of the remix: an anarchaeology of digital media creation processes}

Lucia Leão

1 Este artigo é uma versão revista e atualizada do artigo apresentado no XXI Encontro da Associação Nacional dos Programas de Pós-Graduação em Comunicação (Compós), realizado em junho de 2012 na Universidade Federal de Juiz de Fora (UFJF). 


\section{Resumo}

As mídias digitais, os bancos de dados e a lógica do software povoam a cultura contemporânea. Nesse cenário, procedimentos específicos de criação e produção de linguagem emergem nas redes. Compreendido enquanto ato de editar fragmentos de materiais pré-existentes com o objetivo de gerar novas obras, o remix é uma prática característica da cultura digital. Este artigo inicia com uma revisão crítica a respeito da discussão sobre o remix na cultura digital (Lessig, Manovich, Navas); em seguida, discute o remix como procedimento criativo nas diferentes mídias e como escolha estética na produção de imagem e imaginário midiáticos. A colagem segundo a visão de Max Ernst é revisitada para traçar paralelos com os processos de acoplamentos do remix. Para pensar o remix enquanto linguagem, realizamos dois estudos de caso.

Palavras-chave

Teorias da imagem, mídias digitais, processos de criação nas mídias, remix.

\section{Abstract}

Digital media, databases and the logic of the software settle the contemporary culture. In this context, specific procedures of creation and production of language emerge from networks. Being the act of editing fragments of preexisting materials with the aim of generating new works, the remix is a typical digital culture practice. This article starts with a critical revision about the discussion on remix in the digital culture (Lesssig, Manovich, Navas). Then, it discusses the remix as a creative procedure in various media and as an aesthetic choice in the production of media image and imaginary. The montage, according to Max Ernst perspective, is revisited to establish parallels with the remix processes of linking up. In order to study the remix as a language, two case studies are presented.

\section{Keywords}

Theory of the image, digital media, creative processes in media, remix. 
Uma história que vincula imaginação, escuta e a arte da combinação por meio do uso de dispositivos técnicos; que privilegia o sentido de suas possibilidades multifárias em relação a suas realidades, na forma de produtos, não pode ser escrita sem pretensões vanguardistas, ou com disposição mental de mostrar o caminho (ZIELINSKI, 2006, p. 45).

Trabalhar com conteúdos da cultura, recombinar fragmentos, reler notícias, frases, imagens e vídeos são atividades expressivas típicas da cultura remix. A questão que procuramos desenvolver neste artigo é: o remix pode ser empregado como uma escolha intencionalmente estética, tendo em vista a produção de imagens e imaginários midiáticos? Para responder a essa indagação é preciso, antes de qualquer coisa, definir os pontos de partida de nossa pesquisa. Conforme a cartografia de processos de criação que propomos, "os processos de criação se organizam em três categorias que definimos de acordo com as lógicas procedimentais que viabilizam". São elas: (1) processos associativos; (2) processos de projeto; (3) processos de tradução (LEÃO, 2011). Os trabalhos que iremos analisar neste artigo se situam classificados como processos de tradução.

\section{Remix}

As mídias digitais, os bancos de dados e a lógica do software povoam a cultura contemporânea. Nesse cenário, processos específicos de criação e produção de linguagem emergem nas redes. Atividades corriqueiras como "cortar, copiar e colar" desvelam procedimentos que sustentam a cultura do remix. Trabalhar com arquivos, descontruindo e reconstruindo materiais fragmentados, é algo bastante frequente nas práticas das redes, e esses procedimentos possibilitam e facilitam atos de apropriação, releituras e colagens. O termo "remix" circula em diferentes contextos e é utilizado expressivamente na cultura de DJs, VJs, clubes e festas. No âmbito das redes digitais, destaca-se também o fenômeno dos mash-ups, plataformas, projetos e websites que mesclam dados obtidos a partir de provedores de conteúdo diversos em uma interface integrada. 
A abundante utilização de práticas de remix na cultura contemporânea é tão incontestável que o artista e teórico Lev Manovich chegou a afirmar a ser lugar-comum falar que vivemos numa "cultura do remix", à medida que muitos cenários culturais e estilos de vida - música, moda, design, arte, aplicações web - são criados a partir de remixes, fusões ou mash-ups (2007). Em seu estudo, Manovich relaciona a padronização da prática do remix ao desenvolvimento dos aparelhos chamados multi-track mixers, tecnologias capazes de separar em canais diferentes cada instrumento gravado em uma canção.

\begin{abstract}
Remixing originally had a precise and a narrow meaning that gradually became diffused. Although precedents of remixing can be found earlier, it was the introduction of multi-track mixers that made remixing a standard practice. With each element of a song - vocals, drums, etc. - available for separate manipulation, it became possible to "re-mix" the song: change the volume of some tracks or substitute new tracks for the old ounces. Gradually the term became more and more broad, today referring to any reworking of already existing cultural work(s) (2007).
\end{abstract}

Destarte, na proposta conceitual de Manovich, a possibilidade de separar elementos de uma canção é a base. Com esses elementos disponíveis e utilizando lógicas da combinatória, tarefas como trabalhar novas montagens, explorar novos arranjos, incorporar outros elementos, experimentar e construir novas estruturas são facilitadas de modo exponencial.

Um dos pioneiros na utilização de elementos da combinatória em sua experimentação poética, Mark Amerika (2005) é autor de vários projetos e textos críticos nos quais discute e explora o potencial criativo de procedimentos como o remix, o cut-up, a colagem e ready-mades. Na trajetória de Amerika, a questão da remixologia é uma presença imanente. Como exemplos de obras que se tornaram clássicas, podemos citar: Remix the book e Crapshoot: remixing Mallarmé. Este, por sinal, é um projeto artístico que discute importantes questões na área das pesquisas em processos de criação em mídias digitais, à medida que mescla propriedades da arte computacional, lógicas generativas e o famoso 
poema de Stéphane Mallarmé, "Um lance de dados", de 1897. Recentemente, a remixologia de Amerika foi revisitada no vídeo do professor David Gunkel e, mais profundamente, no livro Remixology (2014).

Remix, fazendo arte e comércio prosperar na economia híbrida, livro de Lawrence Lessig, criador do Creative Commons, apresenta o processo de remixagem como algo desejável na cultura. Para Lessig, a criação de riqueza de uma cultura é fundamentalmente ligada a processos de remixagem participativos. Em seu livro, Lessig retoma conceitos da economia do século XIX, contrapõe modelos de negócios comerciais (Amazon, Google etc.) e participativos (Wikipédia) e defende o florescimento de uma economia híbrida na "www" (YouTube, Flickr, Slashdot, entre outros). Esse hibridismo na cultura é, na visão de Lessig (2008, p. 34), a junção da cultura RO (read only) com a RW (read, write). A primeira simplesmente consome - relacionada a atos como ler livros, ir ao cinema etc. e pode ser expandida (LESSIG, 2008); a segunda é participativa, utilizando-se de procedimentos do remix em seus processos criativos. Lessig afirma o valor do remix nas ações participativas: "Remix is an essential act of RW creativity. It is an expression of freedom to 'the songs of the day or the old songs' and creates with them" (2008, p. 56). As manifestações desses impulsos criativos e críticos são percebidas a todo o momento, quer seja nos vídeos publicados no YouTube, quer seja nas várias releituras com tom humorístico que emergem em plataformas diversas, como, por exemplo, no 9gag.

No universo musical, o remix ganha popularidade incomensurável. Nesse cenário, ele é um camaleão com vários sentidos, podendo indicar uma simples utilização ou apropriação de conteúdos pré-existentes ou algo mais específico, como um tipo de arranjo musical que carrega uma ou mais reinterpretações de uma ou mais músicas. Assim, no remix especificamente musical o destaque é a possibilidade de reconhecer uma ou mais músicas originais, seus vestígios.

Eduardo Navas aponta a alegoria como "a parte mais vital do remix", o código cultural que todo remix carrega (em sua formulação teórica, ele adota 
o conceito de alegoria proposto pelo crítico de arte Craig Owens ${ }^{3}$ ). Na sua perspectiva, os procedimentos de desconstrução operam a partir de uma lógica consciente do conteúdo histórico e político que cada objeto artístico carrega. Navas apresenta uma classificação composta por três tipos de remix: o estendido, o seletivo e o reflexivo.

A primeira categoria, remix estendido, fundamenta-se no uso de uma música estendida, ampliada. Muitas vezes, esse remix nada mais é do que uma versão mais longa da canção original. Assim, nesse processo criativo, partes da música são repetidas em diferentes momentos, e uma canção de dois minutos pode vir a durar dez. Embora esse tipo de procedimento seja bastante comum na cultura digital, é possível buscar seus ramos e ecos em diferentes períodos.

O remix seletivo é composto por obras nas quais, embora a "aura" da canção original seja mantida, é possível adicionar sons, fragmentos e samplers de outras composições, ou até mesmo remover partes do original. Um exemplo nas artes visuais de remix seletivo é a releitura de Sherrie Levine a partir do famoso urinol de Duchamp, obra que instaurou a prática do ready-made. Em Fountain (after Marcel Duchamp: A. P.), realizada em 1991, peça produzida por Levine, o urinol não é mais um item industrializado. Fazendo referência ao que esse ready-made representa na arte, Levine o recria como obra única, seguindo métodos da escultura tradicional em bronze. Podemos dizer que o imaginário do mundo artístico foi revisitado e subvertido de forma irônica. Pois, à medida que escolheu transformar a peça em uma escultura de bronze, a artista desvelou o paradoxo do ícone.

O terceiro tipo de remix proposto por Navas, o remix reflexivo, tem maior complexidade, envolve alterações estruturais na música e, muitas vezes, engenharia de software. Nessa última categoria estão os DJs autorais, profissionais criativos que elevam o remix a um patamar estético aprimorado. 0 
trabalho desenvolvido pelo DJ Spooky, que analisaremos mais adiante, situa-se nessa classificação.

No presente artigo, o remix é compreendido em seu sentido amplo, ou seja, enquanto processo de edição e utilização de fragmentos de materiais préexistentes, com o objetivo de gerar novas obras. Embora a utilização desse tipo de procedimento seja frequente nos processos criativos musicais, em outros setores o remix ainda esbarra em problemas conceituais vinculados a questões de autoria e originalidade.

\section{Outras problematizações}

Nas artes visuais, por exemplo, as cópias e os remakes surgem nas trajetórias de vários pintores. É célebre a obsessão que Van Gogh tinha pelo trabalho de Millet e não por acaso realizou uma série de estudos sobre seus quadros. Muitas vezes, as releituras são vistas como "homenagens" que evocam a obra original como fonte inspiradora.

A série Les ménines, de Picasso (1957), por exemplo, é composta por vários estudos da famosa pintura de Velázquez (1656), Las meninas. Pode-se observar que as mudanças propostas por Picasso partem de investigações de natureza cromática e gestual e caminham rumo a uma abstração. O mesmo procedimento de estudo imagético está presente na releitura que Picasso fez da obra O rapto das Sabinas, de Nicolas Poussin (1637-1638). Na tela de Picasso (1962), pode-se perceber as pinceladas gestuais e as escolhas cromáticas do gênio catalão coexistindo com a "aura" da pintura de Poussin, a mesma composição e enquadramento. As imagens que as releituras nos oferecem são um convite para a recuperação de traços de um museu pictórico. Um museu de imagens que associamos a uma tradição, a um sistema. Não diferentemente dos remixes musicais, são obras que repetem padrões (no caso, uma determinada imagem). E, através dessas repetições, dessas retomadas, as homenagens nos permitem perceber que o imaginário da história da arte foi revisitado. 
É interessante observar que As meninas são homenageadas constantemente. O artista Herman Braun-Vega, em Double éclairage sur Occident, Velázquez et Picasso ("Luzes duplas no Ocidente, Velázquez e Picasso" - 1987), buscou resgatar a iconografia dos dois grandes mestres da pintura ocidental. Em sua poética, o artista, nascido no Peru, acrescentou à memória pictórica elementos sociais contemporâneos assim como narrativas de cunho pessoal.

Forgetting Velázquez. Las meninas, uma exposição realizada no Museu Picasso em 2008, apresentou 44 interpretações realizadas por Picasso juntamente com obras de outros artistas, como: Salvador Dali, Antonio Saura, Equipo Crónica, Joel-Peter Witkin, Giulio Paolini e Richard Hamilton. Com curadoria de Malén Gual, do Museu Picasso, Barcelona, Gertje R. Utley, curador independente, e Javier Portús, do Museu Nacional do Prado, trata-se de um projeto que aponta para o potencial germinativo das práticas de estudo e releitura imagética. $\mathrm{Na}$ profusão de releituras e na densidade das reflexões a que somos conduzidos, fica evidente que o mergulho no imaginário de Velázquez se traduz em processos criativos nas mais diferentes mídias, caso, por exemplo, do trabalho Las Meninas (1975), de Juan Downey, que combina performance, instalação e vídeo e conta com atores interpretando o papel do Rei Filipe e da Rainha Mariana, além de dançarinos modernos.

\section{Outros procedimentos}

Um procedimento criativo próximo ao remix é a citação. Embora apresentem semelhanças, o ato de citar por si só não implica em remixagem, à medida que o ato de remixar requer um trabalho de alteração e transformação do fragmento que serve como fonte. Em textos acadêmicos, por exemplo, as citações devem respeitar o sentido do texto original, bem como seu contexto. As citações estão presentes em vários projetos de artes visuais, e o que os caracteriza é justamente o fato de que a obra citada aparece como referência explícita. Pode-se dizer que, na citação, a proposta é colocar obras em diálogo, ou, pelo menos, imagens em diálogo. 
O fotógrafo alemão Thomas Struth é autor de uma homenagem à Las meninas de Velázquez que articula a questão da citação de modo crítico. Sua obra - Las meninas by Velásquez (Prado), de 2005 - é uma fotografia tirada no Museu do Prado. No ângulo escolhido pelo artista, pode-se visualizar o célebre quadro, assim como a multidão de pessoas presentes no espaço expositivo. Mas, exatamente pela perspectiva escolhida, "as meninas" a quem o título da obra se refere podem indicar também as garotas vestidas de uniforme escolar que visitam o recinto. Nessa obra, Struth subverte o enquadramento e tira o foco central da obra citada. Ao nos colocar diante da imagem de um museu com visitantes (não um museu qualquer, mas um museu que abriga um ícone da arte ocidental), Struth nos propõe uma reflexão a respeito do papel do público na recepção da obra de arte e, além disso, recoloca a questão do olhar que Foucault já havia analisado. Na pintura de Velázquez, os personagens da cena pictórica dirigem seus olhares para fora do quadro:

Mas, inversamente, o olhar do pintor dirigido para fora do quadro, ao vazio que Ihe faz face, aceita tantos modelos quantos espectadores the apareçam; nesse lugar preciso mas indiferente, o que olha e o que é olhado permutam-se incessantemente... Somos vistos ou vemos?" (FOUCAULT, 1995, p. 21).

No momento em que Thomas Struth nos oferece a imagem do museu, todo o imaginário dos espelhos de Velázquez emerge. As meninas que visitam o museu veem os quadros, mas, simultaneamente, são também vistas pelo olhar do artista.

Pictures of junk, série desenvolvida por Vik Muniz que cita obras de arte clássicas, é outro exemplo a ser analisado. Através de um processo complexo, que envolve a reconstituição de imagens a partir da utilização de detritos e posterior ato fotográfico, Muniz propõe com a citação o resgate de uma obra emblemática da história da arte. Em Narciso, depois de Caravaggio (2005), a ironia da citação está no fato de que objetos colhidos em um lixão compõem a imagem do jovem mítico cuja narrativa afirma sua extrema beleza. Além disso, é importante observar o 
que a obra citada representa no imaginário da história da arte. O artista escolhido por Muniz foi Caravaggio (1571-1610), famoso pintor do período barroco. Narciso é uma das obras-primas mais facilmente reconhecidas da arte ocidental, e, como na música, o reconhecimento e a ideia de pertencimento e conexão são elementos fundantes da estratégia do citacionismo. Mas, voltando às imagens digitais e à questão do remix, Manovich nos fala que:

\footnotetext{
The other older term commonly used across media is "quoting" but I see it as describing a very different logic than remixing. If remixing implies systematically rearranging the whole text, quoting refers inserting some fragments from old text(s) into the new one. Thus I think we should not see quoting as a historical precedent for remixing. Rather, we can think of it as a precedent for another new practice of authorship practice that, like remixing, was made possible by electronic and digital technology sampling (2007).
}

Em outras palavras, para Manovich, a citação não seria um precedente histórico do remix, mas sim do sampling (sampleamento). Embora o autor procure estabelecer distinções claras entre esses dois processos de criação (remix e sampling), no presente artigo escolhemos adotar uma abordagem que verifica as zonas de hibridização e/ou mestiçagem entre esses dois sistemas. À medida que nosso foco de interesse é verificar como o remix pode ser uma escolha estética no processo de criação de imagens e imaginários, foi importante buscar projetos de natureza sincrética, ou seja, com aspectos tanto de remix como de sampleamento e citação. Além disso, um dos trabalhos que escolhemos analisar, de autoria de Paul Dennis Miller - DJ Spooky -, parte justamente de uma visão na confluência desses dois processos. Mas, podemos nos perguntar, quais seriam as relações entre o remix e a colagem?

\section{Colagem}

A colagem, em seu percurso histórico, é um procedimento criativo que acompanha a cultura em vários momentos e adquire características específicas em cada um deles. Conforme o amplo estudo desenvolvido por Janis e Blesh 
(1967), procedimentos de colagem estão presentes em passatempos, no desenho ornamental e no artesanato. O século XX vê surgir um interesse pela colagem em diversos de seus movimentos artísticos (dadaísmo, futurismo, surrealismo, construtivismo, entre outros). No cubismo, por exemplo, Braque e Picasso experimentaram a colagem buscando explorar recortes, formas, texturas e materiais variados. São emblemáticas desse estilo as colagens que trazem recortes na forma de violões e palhinhas de cadeira. Nesse tipo de colagem, o processo de recortar e colar é bem marcado, assim como a exploração de elementos gráficos e padrões a partir da incorporação imagética da superfície anexada.

Numa linha investigativa bem diversa, podemos situar os trabalhos que Max Ernst optou por denominar collage. Suas primeiras experimentações com essa técnica foram colagens com pinturas feitas sobre imagens de outras fontes, por volta de 1919, no período em que estava em Colônia. Ele utilizava desde ilustrações de livros, catálogos, revistas, encartes de jornais, propagandas, fotografias, até mesmo reproduções de obras de arte do século XIX. Observa-se um interesse na criação de figuras híbridas, e, assim, suas imagens combinam figuras humanas com pássaros, animais e máquinas, máscaras etc. Além disso, essa técnica desenvolvida revela um esforço no sentido de ocultar a distinção dos elementos colados, buscando construir uma imagem única, integrada. Muitas vezes, para obter esse efeito, Ernst fotografava a colagem criada para diluir as arestas entre as imagens. Warlick (2001), em sua crítica aos processos de Ernst, afirma que colagem para Max Ernst é uma forma de alquimia.

No projeto Une semaine de bonté, romance gráfico concluído em 1933, Ernst utilizou como fontes de suas colagens ilustrações de um romance 1883 por Jules Mary, Les damnées de Paris, gravuras de Gustave Doré, entre outros materiais do século XIX. Especificamente nessas colagens, pode-se observar o cuidado no recorte do contorno das figuras com o objetivo de elaborar imagens híbridas. No imaginário criado por Ernst, monstros e homens compartilham corpos, máquinas e animais se metamorfoseiam e coexistem em ambientes 
sombrios. Outra estratégia encontrada nos romances de colagens de Ernst é o uso de repetição e serialização. Para Spies (1991), são dispositivos estruturantes, módulos paratáticos que induzem à inteligibilidade narrativa. Complementamos: a repetição de imagens cria ritmos e ciclos que ajudam no processo da construção de um imaginário fantástico, habitado por figuras de beleza estranha, incongruente e enigmática.

Para o presente artigo, escolhemos discutir o conceito de collage de Ernst, pois consideramos sua pertinência para a reflexão crítica sobre os processos de criação com o remix. Vejamos como o artista pensa o mecanismo da colagem.

Como se sabe, o poeta romântico Lautréamont foi a inspiração para o texto no qual Ernst apresenta sua teoria da colagem. Seu ponto de partida, a imagem poética: "Belo como o encontro casual de uma máquina de costura e um guarda-chuva sobre a mesa cirúrgica". Sim, nem só de tesoura e cola se faz uma poética da collage. É preciso ir além. É preciso acoplar, pois, para Ernst, colagem é o... "acoplamento de duas realidades aparentemente inacopláveis sobre um plano que aparentemente não Ihes convém" (1996, p. 432).

Podemos interpretar essa fala como: trabalhar com imagens advindas de universos díspares, dando a elas um espaço de convivência, de conversação. Se adotamos esse procedimento, temos que lidar com as dificuldades de estabelecer elos, pontes entre esses mundos. Além disso, vamos adentrar no processo de transformar imagens desconexas em imagens híbridas. Camadas de tintas, veladuras, transparências, foram os recursos que Ernst utilizou. Na cultura do remix, layers e filtros cumprem essas funções.

Dois anos mais tarde, Ernst reinventa seu método de colagem e passa a denominá-lo ubermahlung (sobrepintura). Nessa técnica, o procedimento é inverso à colagem; se na primeira o artista trabalha por adições, na sobrepintura ele inicia com uma imagem impressa que recebe coberturas de camadas de tintas opacas que velam elementos, gerando uma nova imagem. Um exemplo de obra que adota esse processo é La puberté proche... ou les pléiades, que apresenta um corpo nu feminino em suspensão sobre um fundo azul. O corpo é desprovido de 
cabeça e, abaixo da imagem, temos um texto poético escrito em caligrafia manual. Ao trabalhar por subtração, Ernest retira, exclui, "deleta" elementos (KRAUSS, 1994, p. 46). Esse procedimento pode ser visto em vários projetos de remix que editam obras pré-existentes, excluindo dados e construindo novas narrativas.

Vejamos agora estudos de casos que trabalham com acoplamentos de imagens estrangeiras.

\section{Estudos de caso}

O vídeo Read my lips, de Johan Soderberg (2002), é um remix no qual se evidencia a importância dos procedimentos de "cortar/copiar/colar". Vejamos por quê. Soderberg é editor, diretor de filmes, videomaker e artista ${ }^{4}$. Nesse trabalho, editou imagens de Tony Blair e George W. Bush com a música "Endless Love", cantada na voz de Diana Ross e Lionel Richie. Se o artista resolvesse criar ele próprio as imagens e uma canção, o vídeo não teria o mesmo impacto. Ou seja, a força dessa obra reside justamente no fato de que são citações de imagens da cultura e, por isso, vêm acompanhadas de seus contextos, suas narrativas e seus imaginários. Estamos diante das imagens noticiosas dos governantes, e a música romântica clichê adiciona um atributo que não seria possível de ser encontrado em uma nova composição. Cada elemento escolhido pelo artista para ser remixado tem um significado próprio anterior ao projeto de remix. O fato é que conhecemos aquela música, reconhecemos as vozes do dueto, sabemos quem são aquelas pessoas na tela. Tudo isso faz com que o vídeo expresse sua mensagem de forma tão radical. Lessig comenta a respeito:

No one can deny the power of this clip, even Bush and Blair supporters, again in part because it trades upon a truth we all - including Bush and Blair supporters - recognizes as true. It doesn't assert the truth. It shows it. And once it is shown, no one can escape its mimetic effect. This video is a virus; once it enters your brain, you can't think about Bush and Blair in the same way again $(2008$, p. 74$)$. 
Avançando ainda mais na reflexão, pode-se dizer que Soderberg, ao reelaborar imagens bastante enraizadas no imaginário da cultura midiática, promoveu um rearranjo do próprio imaginário midiático. Pensemos assim: no imaginário contemporâneo, as imagens de Bush e Blair estariam em um esquema imagético determinado, vinculado a questões de poder, governos, Estado etc. Por outro lado, a canção "Endless Love" nos remete a territórios imagéticos do amor romântico, do clichê. Seguindo uma leitura das imagens segundo a classificação isotópica do imaginário de Gilbert Durand (2002), esse remix mistura imagens do sistema diurno, esquizóide; com uma melodia de imagens do sistema noturno, místico. Ao se apropriar do áudio dessa canção com intenção de associá-la às imagens dos representantes dos EUA e Inglaterra, o artista cria um híbrido. No processo de pós-produção, Soderberg cuidou para que a sincronização labial ficasse quase imperceptível.

Não por acaso, Soderberg nos apresenta Blair na voz feminina, enquanto Bush assume o vocal másculo no dueto. A alegoria é clara, e o remix, mais do que mero procedimento técnico, é um discurso simultaneamente iconoclasta e criador de novas imagens. Pela sua força estética hibridizante, o projeto de Soderberg assume um caráter viral, se espalha nas redes, nas mentes, colonizando imaginários.

A segunda obra escolhida para estudo de caso é Rebirth of a nation (2004), criada por DJ Spooky5 , um remix do filme Birth of a nation (1915). Nessa peça, pode-se dizer que temos processos de desconstrução, retrabalho (remake) e reconfiguração. Spooky é um músico eletrônico experimental hip-hop que atua também como pesquisador e professor acadêmico na prestigiada European Graduate School ${ }^{6}$. Autor do livro Rhythm science (2002) e organizador da coletânea Sound unbound: sampling digital music and culture (2008), é um pensador que se destaca também por sua poética. Em Rebirth of

$5 \quad$ Ver: <http://djspooky.com/>. 
a nation, o artista nos oferece um mosaico de citações do controverso clássico do cinema mudo.

Trata-se de uma experiência de cinema ao vivo (live cinema) que foi apresentada em diversos espaços, como o Lincoln Center, de Nova York, o Teatro Chatelet, em Paris, e a Acrópoles, de Atenas, e que posteriormente recebeu uma versão em DVD. Como se sabe, o filme de Griffith foi baseado no romance e peça de teatro The Clansman, de Thomas Dixon. A narrativa do filme descreve o relacionamento de duas famílias com visões políticas antagônicas durante a Guerra Civil e reconstrução americanas. O filme tem um discurso que apregoa uma supremacia branca, sendo literalmente um exemplo de propaganda racista, com elementos como: presença de artistas brancos para o papel dos negros através da utilização de maquiagem, retratos apologéticos da Ku Klux Klan etc.

À medida que o filme é também considerado um marco na história do cinema comercial, pode-se dizer que a intenção de Miller foi remixar duas histórias. A mais evidente envolveu desconstruir de forma crítica a narrativa de um período da história americana, no qual o racismo predominou. Isso pode ser observado logo no início do projeto: após apresentar um trecho da versão de Griffith, quando a imagem mostra os indivíduos brancos como heróis, Miller insere mudanças sonoras e melódicas imprevisíveis, com características hip-hop e dissonantes e animações gráficas em camadas sobrepostas.

A segunda remixagem diz respeito à história do cinema comercial americano. Como se sabe, a versão de Griffith foi um grande sucesso comercial e é apontada como a origem de Hollywood. Ao inserir batidas de tambor que lembram sons africanos, sinos, címbalos, fragmentos de blues, Miller descontruiu o grande ícone do discurso hegemônico. O que temos na versão remix é a história de uma nação diversa, palimpsesta. A imagem do país unificado, pasteurizado é corrompida, e o filme digitalmente manipulado "recorta/copia e cola" cinematicamente as histórias das diversidades. Nesse sentido, trata-se de um remix que, ao descontruir uma imagem fortemente enraizada na cultura - e 
portanto no imaginário -, de uma forma viral, deposita as sementes de outras histórias, outras imagens e outros imaginários.

Aplicando a classificação isotópica das imagens de Durand (2002), podemos perceber que enquanto o filme de Griffith parte de uma lógica esquizóide, dualista, o remix de Miller nos convida a mergulhar nas pronfundezas caóticas das incertezas, numa narrativa mítica que corresponde em vários momentos a uma descida voluntária ao reino de Hades (sistema noturno) e em outros momentos a ciclos e repetições infinitos (sistema sintético).

\section{Considerações finais}

Neste artigo, o remix foi abordado enquanto elemento da cultura digital, como procedimento criativo nas diferentes mídias e como escolha estética na produção de imagens e imaginários midiáticos. Como elemento da cultura digital, o remix se manifesta em diferentes tipos, de acordo com o grau de referência em relação a uma obra ou mais obras (critérios definidos por Navas: o estendido, o seletivo e o reflexivo). Ao discutirmos o remix nos processos criativos em diferentes mídias, vimos que na música ele se associa ao desenvolvimento de aparatos tecnológicos e a práticas de sampling. Nas artes visuais, o remix percorre caminhos complexos que envolvem questões como cópia, citação, remake, apropriação e colagem.

Para discutir a colagem enquanto escolha estética de produção de imaginários híbridos, partimos em busca de Max Ernst e seus romances gráficos. $\mathrm{Na}$ leitura que empreendemos, as poéticas visuais de Ernst foram vistas como precursoras de métodos contemporâneos de remix digital. Para aplicar a ideia de que o remix pode ser escolha estética na produção de imagens e imaginários midiáticos, escolhemos dois estudos de caso. Nos projetos analisados, buscamos evidenciar que a utilização do remix vai além de um mero recurso tecnológico. Compreendido como procedimento criativo com dimensões lógicas, éticas e estéticas, o remix envolve procedimentos e escolhas conscientes de seus sistemas sígnicos nas mídias. 
Cada fragmento escolhido para um remix carrega consigo seus vínculos culturais, imagéticos e imaginários. Nos novos acoplamentos e recombinações, novas imagens e imaginários são criados. Somente os projetos que articulam essas dimensões exploram o remix enquanto linguagem. Para finalizar, gostaríamos de deixar uma citação do artista e pensador Julio Plaza, que, a nosso ver, sintetiza as tensões que dinamizam os processos de criação em sua relação com a história:

No processo dialético e dialógico da arte não há como escapar à história. A arte se situa na urdidura indissolúvel entre autonomia e submissão [linguagem?]. Filha de sua época, a arte, como técnica de materializar sentimentos e qualidades [tekhné, ars], realiza-se num constante enfrentamento, encontro-desencontro consigo mesma e sua história. Parafraseando Marx: os artistas não operam de maneira arbitrária, em circunstâncias escolhidas por eles mesmos, mas nas circunstâncias com que se encontram na sua época, determinadas pelos fatos e as tradições (2003, p. 5).

\section{Referências}

AMERIKA, M. Escrita no ciberespaço: notas sobre narrativa nômade, net arte e prática de estilo de vida. In: LEÃO, L. (Org.). O chip e o caleidoscópio: reflexões sobre as novas mídias. São Paulo: Senac, 2005. p. 133-146.

BIRTH of a nation. Direção: D. W. Griffith. New York: Kino Lorber, 1915. Disponível em: <https://www.youtube.com/watch?v=I3kmVgQHIEY>. Acesso em: 19 jan. 2017.

DJ SPOOKY. Rebirth of a Nation. 2004. Disponivel em: <https://www.youtube. com/watch?v=3ljIq0lz0qY>. Acesso em: 19 jan. 2017.

DURAND, G. As estruturas antropológicas do imaginário: introdução a arquetipologia geral. São Paulo: Martins Fontes, 2002. 
ERNST, M. Qual é o mecanismo da colagem? In: CHIPP, H. B. (Org.). Teorias da arte moderna. São Paulo: Martins Fontes, 1996. p. 432-433.

FOUCAULT, M. As palavras e as coisas. São Paulo: Martins Fontes, 1995.

GUNKEL, D. J. Of remixology: ethics and aesthetics after remix. Cambridge: MIT, 2016.

JANIS, H.; BLESH, R. Collage: personalities, concepts, technique. Philadelphia: Chilton Co., 1967.

KRAUSS, R. E. The optical unconscious. Cambridge: MIT, 1994.

LEÃO, L. Paradigmas dos processos de criação em mídias digitais: uma cartografia. V!RUS, São Carlos, n. 6, 2011. Disponível em: <http://www.nomads.usp.br/ virus/virus06/?sec=3\&item=1\&lang=pt>. Acesso em: 15 ago. 2016 .

LAS MENINAS. Direção: Juan Downey. New York: MoMA. 1975. 20 min.

LESSIG, L. Remix: making art and commerce thrive in the hybrid economy. New York: Penguin, 2008.

MANOVICH, L. What comes after Remix? 2007. Disponível em: <http://manovich. net/content/04-projects/057-what-comes-after-remix/54_article_2007.pdf>. Acesso em: 11 jan. 2017.

MILLER, P. D. Rhythm science. Cambridge: Mediawork; MIT, 2004. . Sound unbound: sampling digital music and culture. Cambridge: MIT, 2008. 
MUNIZ, V. Pictures of junk. Série de fotografias. Disponível em: <http://vikmuniz. net/gallery/junk>. Acesso em: 19 jan. 2017.

Narciso, depois de Caravaggio. Impressão a cores cromogênica. 2005. Disponível em: <http://warburg.chaa-unicamp.com.br/obras/view/3963>. Acesso em: 19 jan. 2017.

MUSEU PICASSO. Forgetting Velázquez. Las Meninas. 2008. Disponível em: $<$ http://www.museupicasso.bcn.cat/meninas/Forgetting_Velazquez_Las_ Meninas.pdf>. Acesso em: 19 jan. 2017.

NAVAS, E. The three basic forms of remix: a point of entry. 2007. Disponível em: <http://www.remixtheory.net/?p=174>. Acesso em: 17 ago. 2016.

OWENS, C. The allegorical impulse: towards a theory of postmodernism. In: WALLIS, B. (Ed.). Art after modernism: rethinking representation. New York: New Museum of Contemporary Art, 1984.

PICASSO, P. Les ménines. 1957. Série de 58 pinturas. O rapto das sabinas. 1962 . Óleo sobre tela.

POUSSIN, N. O rapto das sabinas. 1637-1638. Óleo sobre tela.

PLAZA, J. Tradução intersemiótica. São Paulo: Perspectiva, 1987.

SPIES, W. Max Ernst collages: the invention of the surrealist universe. Tradução John William Gabriel. New York: Abrams, 1991. 
SODERBERG, J. Read my lips. 2002. Disponível em: <https://www.youtube. com/watch?v=g6-NDTWM8VE>. Acesso em: 19 jan. 2017.

STRUTH, T. Las meninas by Velásquez (Prado). 2005. Fotografia. Disponível em: <http://www.npr.org/2016/10/31/499443750/photography-writ-large-themonumental-art-of-thomas-struth>. Acesso em: 19 jan. 2017.

VEGA, H. B. Double éclairage sur occident, Velázquez et Picasso. 1987. Óleo sobre tela.

VELÁZQUEZ, D. Las meninas. 1656. Óleo sobre tela.

WARLICK, M. E. Max Ernst and alchemy: a magician in search of myth. Austin: University of Texas, 2001.

ZIELINSKI, S. Arqueologia da mídia: em busca do tempo remoto das técnicas do ver e do ouvir. São Paulo: AnnaBlume, 2006.

submetido em: 30 jul. 2016 | aprovado em: 30 ago. 2016 